\title{
Diagnosis and Sero-Epizootiology of Equine Herpesvirus Type 1 and Type 4 Infections in Japan Using a Type-Specific ELISA
}

Sho YASUNAGA, Ken MAEDA*,Tomio MATSUMURA ${ }^{1)}$, Kazushige KAI, Hiroyuki IWATA ${ }^{2)}$ and Takeshi INOUE2 Department of Veterinary Microbiology and ${ }^{2}$ Department of Veterinary Hygiene, Faculty of Agriculture, Yamaguchi University, 16771 Yoshida, Yamaguchi 753-8515, and ${ }^{1)}$ Epizootic Research Station, Equine Research Institute, Japan Racing Association, 1400-4, Shiba, Kokubunji-machi, Shimotsuga-gun, Tochigi 329-0412, Japan

(Received 26 January 1998/Accepted 5 June 1998)

ABSTRACT. Recently, a type-specific ELISA using equine herpesvirus type 1 (EHV-1) and type 4 (EHV-4) glycoprotein Gs (gGs) was developed by Crabb and Studdert [1993]. To investigate the dissemination of EHV-1 and -4 among horses in Japan, we applied their ELISA as suitable for discriminating between EHV-1 and -4 infections serologically. Type-specificity of the ELISA was confirmed by using paired sera of infected horses with either EHV-1 or -4. Application of the ELISA to sera collected before and after the winter season of 1995-1996 from 80 racehorses revealed that 30 horses showed significant antibody responses against EHV-1 and 9 against EHV-4, respectively. The results indicated that this ELISA using paired sera is useful for a diagnosis and an epizootiological study on EHV-1 and -4 infections. - KEY wORDS: diagnosis, epizootiology, equine herpesvirus.

J. Vet. Med. Sci. 60(10): 1133-1137, 1998

Equine herpesvirus types $1(\mathrm{EHV}-1)$ and $4(\mathrm{EHV}-4)$ are causative agents of equine rhinopneumonitis. Both viruses belong to the family Herpesviridae, the subfamily Alphaherpesvirinae. The viruses have been shown a wide geographic distribution and cause serious economic losses worldwide. EHV-1 causes acute upper respiratory disease, central nervous system disorders and contagious virus abortion in horses, and EHV-4 causes respiratory disease and, occasionally, abortion [1]. The difference between EHV-1 and -4 has been demonstrated in pathogenicity in baby mice [11-13], restriction endonuclease analysis of viral DNA [18], and polymerase chain reactions [2, 6, 15]. However, because of the extensive antigenic cross-reactivity, it is difficult to distinguish between EHV-1 and -4 infections by conventional serological tests.

In Japan, only EHV-4 in horses before 1967 was distributed [4, 16]. An occurrence of EHV-1 abortion among imported mares in 1967 caused the first outbreak of EHV-1 abortion among pregnant mares raised in Japan [5]. Thereafter both EHV-1 and -4 spread among various horse populations in Japan. Today, many racehorses at two Training Centers of the Japan Racing Association (JRA) have suffered from respiratory disease with pyrexia by EHV1 or -4 infection [20]. Furthermore, foals and yearlings suffering from respiratory disease on breeding and rearing farms also have been diagnosed serologically to be infected with EHV-1 or -4 [8, 19]. The virological study revealed that EHV-1 caused epizootics of respiratory disease among racehorses exclusively in the winter season, and that EHV4 also caused respiratory disease among racehorses sporadically and among foals and rearing horses irrespective of the season [10].

* Correspondence to: Maeda, K., Department of Veterinary Microbiology, Faculty of Agriculture, Yamaguchi University, 1677-1 Yoshida, Yamaguchi-city, Yamaguchi 753-8515, Japan.
Virological diagnosis can identify the type of infected virus, but they are time-consuming and laborious. Therefore, it is considered to be very important to diagnose the type of infected virus serologically. The purpose of this study was to develop a type-specific serological test for diagnosis of EHV-1 and -4 infections, which facilitates the elucidation of epizootiological characteristics of both infections among the various horse populations in Japan.

The EHV-1 89c25p strain [9] and an EHV-4 strain TH20, the Japanese prototype of EHV-4 [4], were used in this study. Viruses were propagated at low multiplicities of infection in primary fetal horse kidney cells. Infected cells showing a cytopathic effect were treated with $1 \%$ sodium dodecyl sulfate $(\mathrm{SDS})$ and proteinase $\mathrm{K}(0.1 \mathrm{mg} / \mathrm{m} l)$ in 0.1 $\mathrm{M}$ Tris- $\mathrm{HCl}$ (pH 8.0), $0.1 \mathrm{M} \mathrm{NaCl}, 5 \mathrm{mM}$ EDTA at $37^{\circ} \mathrm{C}$ overnight. Following the DNA extraction with phenol and chloroform-isoamyl alcohol (24:1), ethanol precipitated preparations were dissolved in water.

Crabb and Studdert [3] reported that type-specific, continuous epitopes were located in the corresponding $C$ terminal variable region of EHV-1 gG (amino acids 288 to 350 ) and EHV-4 gG (amino acids 287 to 382), which show little amino acid identity. To express the type-specific antigen, the bacterial expression plasmid pGEX-5X1 was used. The recombinant pGEX-5X1 plasmids, pGEX-gG1P and pGEX-gG4P, were constructed according to the methods described previously [3] with a minor modification. (i) pGEX-gG1P was constructed by PCR amplification (35 cycles of $92^{\circ} \mathrm{C}$ for $1 \mathrm{~min}, 55^{\circ} \mathrm{C}$ for $1 \mathrm{~min}, 72^{\circ} \mathrm{C}$ for $1 \mathrm{~min}$ ) with the EHV-1 89c25p DNA as the template and the following primers: forward primer, gG1P-F, containing an EcoRI site, 5'-CCGAATTCGGTGACGAAACATACGA-3', and reverse primer, gG1P-R, containing an XhoI site, 5'AACTCGAGCTGGATGCCGTTCGACG-3'. The amplified fragment was digested with EcoRI and XhoI and cloned into the pGEX-5X1 digested with the same restriction endonucleases. (ii) pGEX-gG4P was constructed by PCR amplification $\left(35\right.$ cycles of $92^{\circ} \mathrm{C}$ for $1 \mathrm{~min}, 50^{\circ} \mathrm{C}$ for $1 \mathrm{~min}$, 
$72^{\circ} \mathrm{C}$ for $1 \mathrm{~min}$ ) with the EHV-4 TH20 DNA as the template and following primers: forward primer, gG4P-F, containing an EcoRI site, 5'-CCGAATTCGAAAATGAAACCTACAG3', and reverse primer, gG4P-R, containing an XhoI site, 5'-AACTCGAGGAGGCCATGCAACACAC-3'. The amplified fragment was cloned into the pGEX-5X1 in the same manner with pGEX-gG1P. Escherichia coli XL1blue strains containing the correct recombinant plasmids were identified, and glutathione S-transferase (GST) fusion proteins were purified by a method based on that of Smith and Johnson [17].

For analysis of the expression products, SDSpolyacrylamide gel electrophoresis (PAGE) and immunoblot analysis were carried out. SDS-PAGE was carried out with the discontinuous Laemmli buffer system [7]. All samples were dissolved in the buffer $(62.5 \mathrm{mM}$ Tris-HCl, $\mathrm{pH} 6.8$, $20 \%$ glycerol, $2 \%$ SDS, and $0.001 \%$ bromophenol blue), and then disrupted by heating for $2 \mathrm{~min}$ at $100^{\circ} \mathrm{C}$. Polypeptides were separated on a $15 \%$ SDS-PAGE. The gel was stained with $0.006 \%$ Coomassie Brilliant Blue in $10 \%$ acetic acid. The result showed that the major fusion proteins produced by pGEX-gG1P and pGEX-gG4P had molecular weights (MWs) of approximately 37 and $36 \mathrm{kDa}$ respectively (data not shown). These sizes are similar to the predicted sizes of GST-gG1P and GST-gG4P fusion proteins. Next, in order to examine the type-specificity of the expressed fusion proteins, immunoblot analysis using sera collected from experimentally infected horses with EHV-1 or -4 was carried out. The fusion proteins, GSTgG1P and GST-gG4P, specifically reacted with EHV-1-infected foal serum and EHV-4-infected yearling serum, respectively (data not shown). It was confirmed that the variable region of EHV-1 and -4 gGs used in this study contained type-specific epitopes, as reported previously [3].

Crabb and Studdert have reported a single-dilution typespecific ELISA using these recombinant $\mathrm{gG}$ fusion proteins [3]. To improve their ELISA method for serological diagnosis of EHV-1 and -4 infections to simplify the estimation of test results, we used serially diluted paired sera. The procedure for the ELISA is as follows: GST fusion or GST protein diluted in the adsorption buffer $(0.05$ M Carbonate-bicarbonate buffer $\mathrm{pH} 9.6$ ) were dispensed into the wells of flat-bottomed 96-well microplates (Flow Laboratories, Inc., U.S.A.) in $50 \mu l$ aliquotes. The plates were covered and stored at $4^{\circ} \mathrm{C}$ overnight for adsorption of antigen. The plates were replaced with $100 \mu l$ of PBS containing $0.1 \%$ bovine serum albumin for blocking. After incubation at $37^{\circ} \mathrm{C}$ for $60 \mathrm{~min}$, the blocking solution was discarded and $50 \mu \mathrm{l}$ of the test serum, serially diluted in PBS containing $0.05 \%$ Tween 20 (PBST) supplemented with $10 \%$ calf serum (CS), was added to each well. After incubation at $37^{\circ} \mathrm{C}$ for $60 \mathrm{~min}$, the plates were washed 6 times with PBST, and then $50 \mu l$ of horse radish peroxidase (HRP) labeled goat anti-horse IgG antibody (Chemicon International, Inc., U.S.A.), diluted to $1: 1,000$ in PBST supplemented with $10 \% \mathrm{CS}$, was added to each well. After incubation for $60 \mathrm{~min}$ at $37^{\circ} \mathrm{C}$, the plates were washed 6 times with PBST, and then a substrate solution, containing $0.1 \mathrm{M}$ citric acid, $0.2 \mathrm{M}$ sodium phosphate, $0.003 \% \mathrm{H}_{2} \mathrm{O}_{2}$ and $0.3 \mathrm{mg} / \mathrm{ml}$ of 2,2'-Azino-di-[3-ethylbenzthiazoline sulfonate], was added to each well in $100 \mu \mathrm{l}$ aliquotes. The absorbance at 405-nm was read after incubation for $30 \mathrm{~min}$, using a micro-ELISA reader. The ELISA titer was expressed as the reciprocal of the maximum dilution that showed an ELISA value, which is the absorbance difference between the GST fusion protein and GST protein, equal to or over 0.1 .

To determine the most appropriate concentration of the GST fusion proteins to use as ELISA antigens for antibody detection, box titration was carried out using EHV-1 or -4 infected horse serum. A concentration of $0.2 \mu \mathrm{g} / \mathrm{m} l$ was indicated as the most appropriate for both types of GST fusion protein (data not shown). Hereafter, GST and GST fusion proteins were used at the concentration of $0.2 \mu \mathrm{g} / \mathrm{m} l$.

To examine the availability of this ELISA system, sera collected from horses which were experimentally infected with EHV-1 or -4 were applied to this system (Fig. 1). Serum samples were collected from three foals (No. 1-3; correspond to R-1 - R-3 in reference 9) which were experimentally inoculated with EHV-1 89c25p gE-gI-rev [9], similar phathogenicity and virus growth to the parent strain, 89c25p, and three yearlings (No. 4-6) which were experimentally inoculated with EHV-4 TH20 strain. Figure $1 \mathrm{~A}$ exhibited that 14 days after EHV-1 infection, sera of horses showed over 4-fold higher titers against EHV$1 \mathrm{gG}$ than preinfection sera, but less than 2-fold higher titers against EHV-4. In spite of no detectable level of virus neutralizing (VN) antibody, the ELISA could detect the rise of antibody against EHV-1 (Fig. 1, No. 2). Figure $1 \mathrm{~B}$ exhibited that 14 days after EHV-4 infection, sera of horses showed over 16-fold higher titers against EHV-4 gG than preinfection sera, but less than 2-fold higher titers against EHV-1. These results suggested that this ELISA method is type-specific and possesses a high sensitivity. From these results, we tentatively defined that EHV-1 or -4 infection is diagnosed by 4 -fold rise of ELISA titer between paired sera.

For further analysis of the specificity, we examined the ELISA titers of paired sera collected at acute and convalescent phases from 16 febrile racehorses (No. 1-16) in which a tentative serological diagnosis of EHV-1 or -4 infection was made by complement fixation (CF) test. The result showed that a final diagnosis of EHV-1 infection was made in 8 horses and that diagnosis of EHV-1 infection might be made in another 3 horses (Table 1). On the other hand, no racehorse was diagnosed as EHV-4 infection. We also carried out ELISA on paired sera collected from 9 foals and rearing horses (No. 17-25) with pyrexia from which EHV-4 strains were isolated. In 7 horses, ELISA titers against EHV-4 gG rose significantly, but they did not in 2 foals, No. 17 and No. 18 (Table 1). Since these two foals were under three-months of age, the maternal antibody from colostrum might have affected their antibody responses to the EHV-4 infection. These results suggested that this 

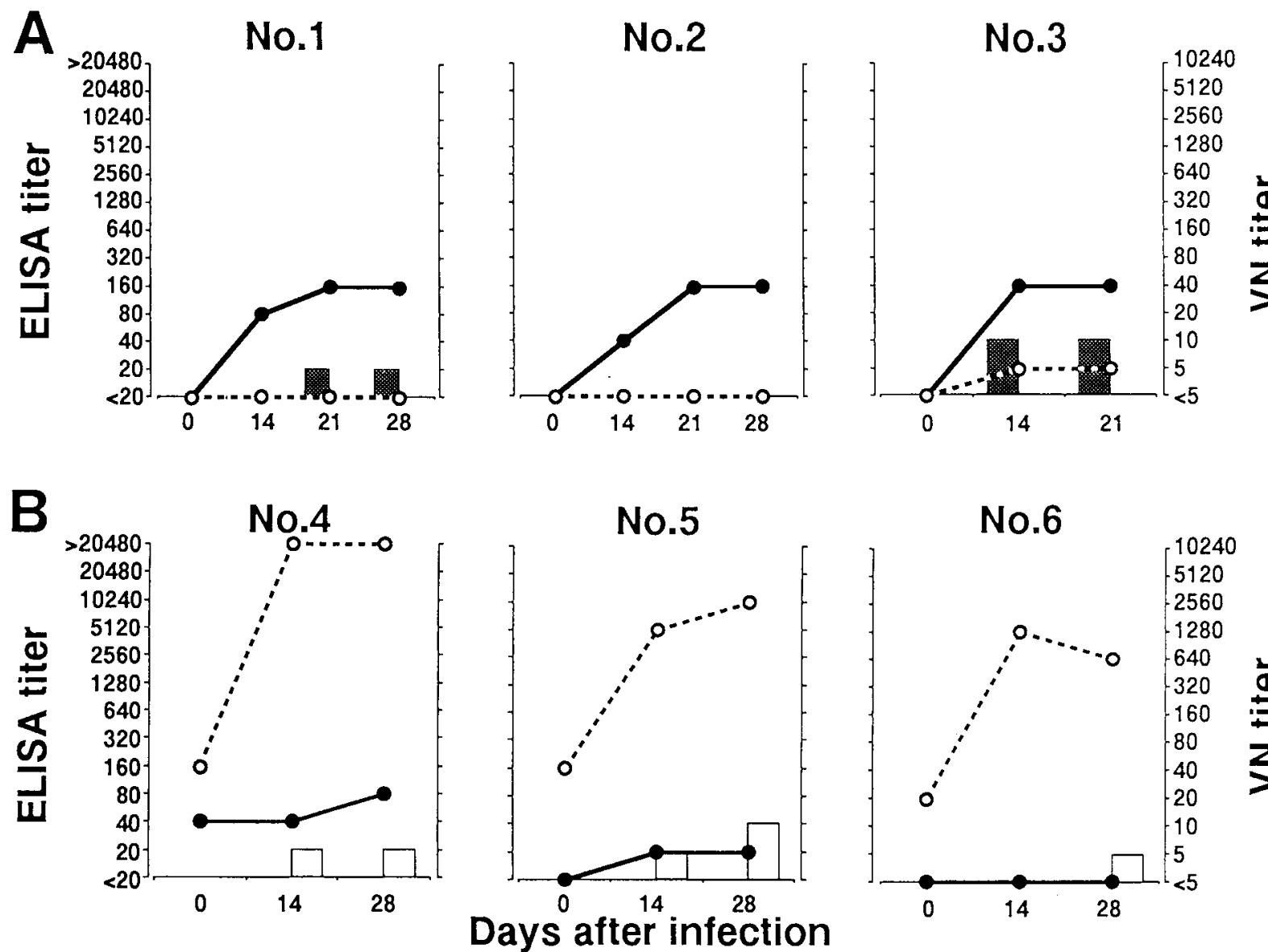

Fig. 1. ELISA titers of sera collected from experimentally infected horses with EHV-1 or EHV-4. (A) ELISA titers of sera collected from experimentally infected foals with EHV-1. (B) ELISA titers of sera collected from experimentally infected yearlings with EHV-4. Closed and open columns show VN titers against EHV-1 and EHV-4, respectively. Closed and open circles show ELISA titers against EHV-1 and EHV-4 gGs, respectively.

ELISA method might be useful for a definitive diagnosis of EHV-1 and -4 infections.

For epizootiological study on EHV-1 and -4 infections among racehorses in Japan, sera were collected before and after the winter season of 1995-1996 from 80 racehorses at Ritto and Miho Training Centers of the JRA (Table 2). ELISA titers against EHV-1 gG significantly rose in 30 $(37.5 \%)$ out of 80 horses and those against EHV-4 gG rose in $9(11.25 \%)$. These results were consistent with previous reports that EHV-1 is responsible for epizootic respiratory diseases in racehorses in winter [10, 20], and revealed that EHV-4 is also sporadically responsible for respiratory disease among racehorses during the period. In addition, sera of two horses (Table 2, M28 and M42) reacted to both antigens. Since most of the EHV-1 or -4 infected horses judged by the ELISA (35 out of $37,94.6 \%$ ) showed an antibody rise only against one of the antigens in their sera, it was suggested that the two horses were infected with both EHV-1 and -4 at a certain time or times during the period between the time points of sample collection.

In this study, it became possible to make a definitive diagnosis of EHV-1 or -4 infection using paired sera.
However, in some cases, results of ELISA did not consist with those of CF test. We speculated that because of different antigens between $\mathrm{gG}$ fusion proteins for ELISA and whole extracts of EHV-1-infected cells for CF test, reactivity of antibody might be different, or that antigenicity of certain field viruses might be different from that of $89 \mathrm{c} 25 \mathrm{p}$ used in this study. Furthermore, ELISA titers against EHV-4 gG were higher than those against EHV-1 $\mathrm{gG}$ in most sera including the sera from experimentally infected horses, although similar VN antibody titers against the homologous virus were observed in those sera (see Fig. 1). Therefore, it is thought that immunogenicity of the EHV-4 gG might be higher than that of the EHV-1 gG. Further analysis would be required to resolve these problems.

In conclusion, the ELISA method using paired sera and judging by a 4-fold rise of antibody titer between paired sera might be useful both for diagnosis and for epizootiological studies on EHV-1 and -4 infections, which had been previously thought to be difficult to carry out serologically. 
Table 1. ELISA titers of paired sera collected from horses with pyrexia

\begin{tabular}{|c|c|c|c|c|c|c|}
\hline \multirow{3}{*}{$\begin{array}{c}\text { Horse }^{\mathrm{a})} \\
\text { no. }\end{array}$} & \multirow{2}{*}{\multicolumn{2}{|c|}{ Date of collection }} & \multicolumn{4}{|c|}{ ELISA titers against } \\
\hline & & & \multicolumn{2}{|r|}{ EHV-1 } & \multicolumn{2}{|c|}{ EHV-4 } \\
\hline & acute & convalescent & acute & convalescent & acute & convalescent \\
\hline 1 & Mar/17/1996 & Apr/19/1996 & 20 & $80 * *$ & 160 & 160 \\
\hline 2 & Mar/23/1996 & Apr/12/1996 & $<20$ & $320 * *$ & 1280 & 2560 \\
\hline 3 & Mar/7/1996 & Mar/27/1996 & $<20$ & $20^{*}$ & 320 & 320 \\
\hline 4 & Feb/28/1996 & Mar/15/1996 & $<20$ & $40 * *$ & 160 & 160 \\
\hline 5 & Apr/8/1996 & Apr/26/1996 & $<20$ & $20^{*}$ & 1280 & 1280 \\
\hline 6 & Jan/19/1996 & Feb/9/1996 & 40 & 80 & 640 & 320 \\
\hline 7 & Jan/30/1996 & Feb/16/1996 & 40 & $320 * *$ & 640 & 320 \\
\hline 8 & Feb/8/1996 & Feb/23/1996 & $<20$ & $80^{* * *}$ & 160 & 320 \\
\hline 9 & Feb/9/1996 & Mar/1/1996 & $<20$ & $160^{* *}$ & 320 & 320 \\
\hline 10 & Mar/24/1996 & Apr/12/1996 & 40 & 40 & $>2560$ & 2560 \\
\hline $11^{\mathrm{b})}$ & Jan/4/1989 & Jan/15/1989 & $<20$ & $20 *$ & 320 & 160 \\
\hline 12 & Jan/5/1989 & $\operatorname{Jan} / 21 / 1989$ & 20 & 40 & 320 & 640 \\
\hline 13 & Jan/6/1989 & Jan/21/1989 & 160 & 320 & 1280 & 640 \\
\hline $14^{\mathrm{c})}$ & Jan/6/1989 & $\operatorname{Jan} / 22 / 1989$ & 20 & $640 * *$ & 160 & 160 \\
\hline 15 & Jan/9/1989 & Jan/25/1989 & 640 & 640 & 1280 & 2560 \\
\hline $16^{\mathrm{c})}$ & Jan/11/1989 & $\operatorname{Jan} / 23 / 1989$ & 40 & $160 * *$ & 1280 & 1280 \\
\hline $17^{\mathrm{d})}$ & Jan/3/1987 & Jul/8/1987 & 40 & 40 & 40 & 40 \\
\hline $18^{\mathrm{d})}$ & Jun/3/1987 & Jul/8/1987 & 20 & 20 & 160 & 80 \\
\hline $19^{\text {d) }}$ & Jul/8/1987 & Sep/1/1987 & 20 & 20 & 320 & $2560 * *$ \\
\hline $20^{\mathrm{d})}$ & Jul/7/1987 & Sep/1/1987 & $<20$ & $<20$ & 160 & $1280 * *$ \\
\hline $21^{\mathrm{d})}$ & Jul/8/1987 & Sep/1/1987 & 20 & 20 & $<20$ & $320 * *$ \\
\hline $22^{\mathrm{d})}$ & Feb/10/1988 & Mar/9/1988 & $<20$ & 20 & 160 & $1280^{* *}$ \\
\hline $23^{\mathrm{d})}$ & Feb/10/1988 & Mar/9/1988 & 40 & 40 & 640 & $>2560 * *$ \\
\hline $24^{\mathrm{d})}$ & Oct/11/1988 & Nov/11/1988 & $<20$ & 20 & 160 & $>2560 * *$ \\
\hline $25^{\mathrm{d})}$ & Oct/12/1988 & Oct/26/1988 & 20 & 40 & 320 & $>2560 * *$ \\
\hline
\end{tabular}

a) No. 1-16; racehorses, No. 17-25; foals and rearingmares. b) EHV-1 was isolated from the horse. c) Nervous disorders were observed in the horse. d) EHV-4 was isolated from the horse. **; Significant antibody response. *; Probably significant antibody response.

ACKNOWLEDGEMENT. We thank the veterinary staffs of the JRA for collecting serum samples.

\section{REFERENCES}

1. Allen, G. P. and Bryans, J. T. 1986. Prog. Vet. Microbiol. Immunol. 2: 78-144.

2. Ballagi-Pordany, A., Klingeborn, B., Flensburg, J. and Belak, S. 1990. Vet. Microbiol. 22: 373-381.

3. Crabb, B. S. and Studdert, M. J. 1993. J. Virol. 67: 63326338.

4. Kawakami, Y., Kaji, T., Ishizaki, R., Shimizu, T. and Matumoto, M. 1962. Jpn. J. Exp. Med. 32: 211-229.

5. Kawakami, Y., Nakano, K., Kume, T., Hiramune, T. and Murase, N. 1970. Bull. Natl. Inst. Anim. Health 61: 9-16 (in Japanese).

6. Kirisawa, R., Endo, A., Iwai, H. and Kawakami, Y. 1993. Vet. Microbiol. 36: 57-67.

7. Laemmli, U. K. 1970. Nature (Lond.) 227: 680.

8. Matsumura, T., Komano, M., Sugiura, T. and Fukunaga, Y. 1986. Bull. Equine Res. Inst. 23: 28-34.

9. Matsumura, T., Kondo, T., Sugita, S., Damiani, A. M., O'challaghan, D. J. and Imagawa, H. 1998. Virology 242:
$68-79$.

10. Matsumura, T., Sugiura, T., Imagawa, H., Fukunaga, Y. and Kamada, M. 1992. J. Vet. Med. Sci. 54: 207-211.

11. Nowotny, N., Burtscher, H. and Burki, F. 1987. J. Vet. Med. B 34: 441-448.

12. Palfi, V. and Christensen, L. S. 1995. Vet. Microbiol. 47: 199-204.

13. Patel, J. R. and Edington, N. 1983. Vet. Microbiol. 8: 301305.

14. Sabine, M., Robertson, G. R. and Whalley, J. M. 1981. Aust. Vet. J. 57: 148-149.

15. Sharma, P. C., Cullinane, A. A., Onions, D. E. and Nicolson, L. 1992. Equine Vet. J. 24: 20-25.

16. Shimizu, T., Ishizaki, R., Ishii, S., Kawakami, Y., Kaji, R., Sugimura, K. and Matumoto, M. 1959. Jpn. J. Exp. Med. 29: 643-649.

17. Smith, D. B. and Johnson, K. S. 1988. Gene 67: 31-40.

18. Studdert, M. J., Simpson, T. and Roizman, B. 1981. Science 214: 562-564.

19. Sugiura, T., Ando, Y., Masuzawa, H., Kuriyama, H., Ogawa, A. and Hirasawa, K. 1983. Bull. Equine Res. Inst. 20: 48-54 (in Japanese).

20. Sugiura, T., Matsumura, T., Fukunaga, Y. and Hirasawa, K. 1987. Jpn. J. Vet. Sci. 49: 1087-1096. 
Table 2. ELISA titers of sera collected from racehorses before and after the winter season of 1995-1996

\begin{tabular}{|c|c|c|c|c|c|c|c|c|c|c|c|}
\hline \multirow{3}{*}{$\begin{array}{c}\text { Horse } \\
\text { no. }\end{array}$} & \multirow{3}{*}{ Sex } & \multicolumn{4}{|c|}{ ELISA titers against } & \multirow{3}{*}{$\begin{array}{c}\text { Horse } \\
\text { no. }\end{array}$} & \multirow{3}{*}{ Sex } & \multicolumn{4}{|c|}{ ELISA titers against } \\
\hline & & \multicolumn{2}{|c|}{ EHV-1 } & \multicolumn{2}{|c|}{ EHV-4 } & & & \multicolumn{2}{|c|}{ EHV-1 } & \multicolumn{2}{|c|}{ EHV-4 } \\
\hline & & Oct, 1995 & May, 1996 & Oct, 1995 & May, 1996 & & & Oct, 1995 & May, 1996 & Oct, 1995 & May, 1996 \\
\hline $\mathrm{R} 1$ & $\hat{\delta}$ & 20 & $<20$ & 2560 & 1280 & M1 & $\hat{o}$ & 80 & $1280 * *$ & 2560 & 640 \\
\hline $\mathrm{R} 2$ & $\hat{0}$ & 40 & 20 & 2560 & 2560 & M2 & 우 & $<20$ & $160 * *$ & 40 & 40 \\
\hline R3 & $\hat{\jmath}$ & 40 & 40 & 2560 & 2560 & M3 & 今 & 80 & 40 & 320 & $1280 * *$ \\
\hline $\mathrm{R} 4$ & $\hat{\delta}$ & 40 & 40 & 640 & $>2560 * *$ & M5 & 우 & 40 & 80 & 640 & 320 \\
\hline R5 & 우 & 20 & $<20$ & 1280 & 1280 & M6 & $\hat{\jmath}$ & $<20$ & $80 * *$ & 640 & 640 \\
\hline R6 & 우 & 80 & 80 & 2560 & 2560 & M7 & $\hat{\jmath}$ & 160 & 160 & 320 & $1280 * *$ \\
\hline R7 & $\hat{0}$ & 20 & $320 * *$ & 1280 & 1280 & M8 & $\hat{0}$ & 20 & $320 * *$ & 80 & 40 \\
\hline R8 & $\hat{\delta}$ & 80 & $1280 * *$ & $>2560$ & 2560 & M9 & 우 & $<20$ & $<20$ & 640 & 320 \\
\hline R9 & $\hat{0}$ & 20 & $80 * *$ & 1280 & 1280 & M11 & $\hat{\delta}$ & 40 & $320 * *$ & 320 & 320 \\
\hline R10 & 우 & 20 & $<20$ & 2560 & 2560 & M12 & 우 & 20 & 20 & 320 & 640 \\
\hline R11 & $\hat{0}$ & 40 & $320 * *$ & 1280 & 1280 & M13 & $\hat{\delta}$ & 80 & 160 & 640 & 1280 \\
\hline R12 & 우 & 20 & $320 * *$ & 1280 & 640 & M14 & $\hat{o}$ & 80 & 160 & 640 & 1280 \\
\hline R13 & 우 & 160 & 80 & 2560 & $>2560(* *)$ & M15 & 우 & 80 & 160 & 320 & 320 \\
\hline R14 & $\hat{\delta}$ & $<20$ & $<20$ & 320 & 160 & M16 & 우 & 20 & 20 & 640 & 640 \\
\hline $\mathrm{R} 15$ & $\hat{\jmath}$ & 40 & 40 & $>2560$ & $>2560(-)$ & M17 & 우 & 20 & $80 * *$ & 640 & 320 \\
\hline R16 & $\hat{\jmath}$ & 160 & 320 & 2560 & $>2560(* *)$ & M18 & $\hat{\delta}$ & 20 & $<20$ & 2560 & 640 \\
\hline R17 & 우 & 160 & 80 & $>2560$ & $>2560(-)$ & M19 & $\hat{o}$ & 20 & $80 * *$ & 160 & 320 \\
\hline R18 & $\hat{0}$ & 20 & $320 * *$ & 2560 & 2560 & M20 & 우 & 1280 & 640 & 320 & 640 \\
\hline R19 & $\hat{0}$ & 20 & $<20$ & $>2560$ & 2560 & M21 & 우 & 320 & 160 & 640 & 640 \\
\hline R20 & 우 & 20 & 20 & $>2560$ & $>2560(-)$ & M22 & 우 & $<20$ & $320 * *$ & 640 & 320 \\
\hline R21 & 우 & 80 & $320 * *$ & 2560 & 2560 & M23 & 우 & 40 & 40 & 640 & 640 \\
\hline R22 & 우 & 320 & $>2560 * *$ & $>2560$ & 2560 & M24 & 우 & 40 & 80 & 320 & 40 \\
\hline R23 & $\hat{\delta}$ & 80 & $320 * *$ & 2560 & 1280 & M25 & 우 & 160 & $640 * *$ & 640 & 640 \\
\hline R24 & $\hat{0}$ & 40 & 40 & 640 & 640 & M26 & 우 & 160 & 160 & 640 & 320 \\
\hline R25 & 今 & 40 & $160 * *$ & 640 & 640 & M27 & $\hat{\jmath}$ & 20 & $640 * *$ & 160 & 320 \\
\hline R26 & 우 & $<20$ & 20 & 2560 & $>2560(-)$ & M28 & 우 & 80 & $320 * *$ & 640 & $2560 * *$ \\
\hline R27 & $\hat{0}$ & 20 & $320 * *$ & 1280 & 1280 & M29 & 우 & 320 & 640 & 160 & 160 \\
\hline R28 & $\hat{0}$ & 80 & 40 & 320 & $2560 * *$ & M30 & 우 & 640 & 640 & 640 & 1280 \\
\hline R29 & 우 & 40 & $320 * *$ & 2560 & 2560 & M31 & 우 & 40 & 20 & 640 & 640 \\
\hline R30 & 우 & 40 & 40 & 2560 & 2560 & M32 & 우 & 40 & $1280 * *$ & 2560 & 2560 \\
\hline R31 & f & 40 & $160 * *$ & $>2560$ & 2560 & M33 & 우 & 160 & 160 & 1280 & 640 \\
\hline R32 & 우 & 40 & 20 & $>2560$ & 1280 & M35 & 우 & 160 & 80 & 640 & 640 \\
\hline R33 & 우 & 80 & 80 & 1280 & $>2560 * *$ & M36 & 우 & 80 & 160 & 320 & 320 \\
\hline R34 & $\hat{\jmath}$ & 20 & 40 & 1280 & 2560 & M37 & 우 & 80 & 160 & 640 & 640 \\
\hline R35 & 우 & 40 & 20 & 2560 & 1280 & M38 & $\hat{\jmath}$ & 160 & 160 & 320 & 640 \\
\hline R36 & $\hat{\jmath}$ & 40 & 40 & $>2560$ & 2560 & M40 & $\hat{\jmath}$ & 40 & $160 * *$ & 2560 & $>2560(-)$ \\
\hline R37 & $\hat{0}$ & 320 & 320 & $>2560$ & 2560 & M41 & $\hat{0}$ & 40 & $320 * *$ & 1280 & 640 \\
\hline R38 & 占 & 40 & 20 & $>2560$ & $>2560(-)$ & M42 & 우 & 80 & $>2560 * *$ & 320 & $1280 * *$ \\
\hline R39 & f & 40 & 40 & 1280 & 1280 & M43 & 우 & 160 & $640 * *$ & 640 & 1280 \\
\hline R40 & $\hat{0}$ & 20 & $160 * *$ & 80 & 160 & M44 & 우 & 40 & 80 & 320 & 320 \\
\hline
\end{tabular}

** Significant antibody response. (**) Singificant antibody response indicated by ELISA using more highly diluted sera. (-) No significant antibody response indicated by ELISA using more highly diluted sera. R; Racehorses in Ritto Training Center of the Japan Racing Association. M; Racehorses in Miho Training Center of the Japan Racing Association. 